\title{
Surface Expression of GluR-D AMPA Receptor Is Dependent on an Interaction between Its C-Terminal Domain and a 4.1 Protein
}

\author{
Sarah K. Coleman, ${ }^{1}$ Chunlin Cai, ${ }^{1}$ David G. Mottershead, ${ }^{1}$ Jukka-Pekka Haapalahti, ${ }^{1}$ and Kari Keinänen ${ }^{1,2}$ \\ ${ }^{1}$ Department of Biosciences (Division of Biochemistry) and ${ }^{2}$ Institute of Biotechnology, University of Helsinki, Helsinki, Finland FIN-00014
}

\begin{abstract}
Dynamic regulation of the number and activity of AMPA receptors is believed to underlie many forms of synaptic plasticity and is presumably mediated by specific protein-protein interactions involving the $\mathrm{C}$-terminal domain of the receptor. Several proteins interacting with the C-terminal tails of the glutamate receptor (GluR)-A and GluR-B subunits have been identified and implicated in the regulation of endocytosis and exocytosis, clustering, and anchoring of AMPA receptors to the cytoskeleton. In contrast, little is known of the molecular interactions of the GluR-D subunit, or of the mechanisms regulating the traffic of GluR-D-containing AMPA receptors. We analyzed the subcellular localization of homomeric GluR-D receptors carrying C-terminal deletions in transfected human embryonic kidney (HEK) 293 cells and in primary neurons by immunofluorescence microscopy and ELISA. A minimal requirement for a 14-residue cytoplasmic segment for the surface expression of homomeric GluR-D receptors was identified. Previously, a similar region in the GluR-A subunit was implicated in an interaction with 4.1 family proteins. Coimmunoprecipitation demonstrated that GluR-D associated with 4.1 protein(s) in both HEK293 cells and rat brain. Moreover, glutathione $S$-transferase pull-down experiments showed that the same 14residue segment is critical for 4.1 binding to GluR-A and GluR-D. Point mutations within this segment dramatically decreased the surface expression of GluR-D in HEK293 cells, with a concomitant loss of the 4.1 interaction. Our findings demonstrate a novel molecular interaction for the GluR-D subunit and suggest that the association with the 4.1 family protein(s) plays an essential role in the transport to and stabilization of GluR-D-containing AMPA receptors at the cell surface.
\end{abstract}

Key words: AMPA receptor; 4.1 protein; surface expression; GluR-D; GluR4; glutamate

\section{Introduction}

Ionotropic glutamate receptors are the major excitatory receptors in the CNS and are divided into three subfamilies on the basis of their ligand selectivity: NMDA, AMPA, and kainate receptors. AMPA receptors are heterotetrameric and/or homotetrameric complexes of GluR-A to GluR-D (or alternatively, GluR1-4) subunits (Hollmann and Heinemann, 1994; Dingledine et al., 1999). Recently, the mechanisms that determine the number and activity of synaptic AMPA receptors have become the focus of intensive research because many forms of synaptic plasticity seem to involve dynamic changes in AMPA receptors (for review, see Bolton et al., 2000; Luscher et al., 2000; Man et al., 2000). In this respect, identification and characterization of molecular interactions between the C-terminal domains (CTDs) of AMPA receptor subunits and other synaptic proteins have drawn considerable attention. By length and sequence similarities, the CTDs of AMPA receptor subunits fall into long (GluR-A and GluR-D) and short (GluR-B and GluR-C) categories. In addition to these

\footnotetext{
Received May 30, 2002; revised Nov. 1, 2002; accepted Nov. 8, 2002.

This work was supported by grants from The Academy of Finland, The National Technology Agency, and the Magnus Ehrnrooth Foundation. We thank Dr. Anthony Baines (University of Kent, Canterbury, UK) for the generous gift of the 4.1N antibody, Taru Kostiainen for technical assistance, and Sami Kaukinen for kindly providing the rat hippocampal neurons.

Correspondence should be addressed to Kari Keinänen, Department of Biosciences, P.0. Box 56, Viikinkaari 5D, 00014 University of Helsinki, Helsinki, Finland FIN-00014. E-mail: kari.keinanen@helsinki.fi.

D. G. Mottershead's present address: Programme for Developmental and Reproductive Biology, Biomedicum Helsinki, Haartmaninkatu 8, University of Helsinki, Helsinki, Finland FIN-00014.

Copyright $\odot 2003$ Society for Neuroscience $\quad 0270-6474 / 03 / 230798-09 \$ 15.00 / 0$
}

major forms, alternative splicing gives rise to relatively less well characterized long and short CTD versions for the GluR-B and GluR-D subunits, respectively (Gallo et al., 1992; Kohler et al., 1994).

Proteins interacting with the CTDs of AMPA receptors have been identified mainly by yeast two-hybrid screens. Thus, a number of PDZ [postsynaptic density-95 (PSD-95)/Discs large (Dlg)/ zona occludens-1 (ZO-1)] domain-containing proteins have been characterized that bind to type II PDZ binding motifs (Sheng and Sala, 2001) that are present in the short CTDs: GRIP1 (Dong et al., 1997), GRIP2/ABP (Srivastava et al., 1998; Dong et al., 1999), PICK 1 (Dev et al., 1999; Xia et al., 1999), and afadin (Rogers et al., 2001). In addition, the $\mathrm{C}$ terminus of GluR-A contains a type I PDZ binding motif that is recognized by PDZ domains of SAP97 (Leonard et al., 1998). Moreover, interactions of AMPA receptor CTDs that do not involve PDZ domains have been identified and include association of $N$-ethylmaleimidesensitive factor with GluR-B (Nishimune et al., 1998; Song et al., 1998) and association of 4.1N and 4.1G with GluR-A (Shen et al., 2000). Remarkably, no proteins interacting specifically with the CTD of GluR-D (long form) have been identified to date. However, several recent studies have reported specific targeting of AMPA receptors that appeared to depend on the GluR-D subunit (Rubio and Wenthold, 1997; Zhu et al., 2000, Keifer, 2001), thereby implying the existence of GluR-D-specific protein interactions.

To identify specific mechanisms controlling the amount of GluR-D-containing AMPA receptors on the plasma membrane, 
we have analyzed the properties and surface expression of homomeric GluR-D receptors carrying C-terminal deletions. We report that a cytoplasmic 14-residue segment proximal to the third transmembrane domain is essential for surface expression of GluR-D in HEK293 cells and in cultured hippocampal neurons, and that GluR-D specifically interacts with $4.1 \mathrm{G}$ and $4.1 \mathrm{~N}$ proteins via this region.

\section{Materials and Methods}

DNA constructs. The expression construct encoding N-terminally Flagtagged GluR-D (P19493; flip isoform) (Sommer et al., 1990) was prepared by inserting the cDNA encoding residues 22-902 (1-21 encode a signal peptide) into a derivative of the pcDNA3.1 plasmid that carries a viral signal peptide followed by an N-terminal Flag epitope and designated as pK710-5. The C-terminal fragments encoding deletion and point mutants were created by PCR and used to replace the native region in pK710-5 after appropriate restriction enzyme digestions. The pcDNA3.1 constructs for the expression of N-terminally Myc-tagged or C-terminally His-tagged GluR-D, or for the N-terminally Flag-tagged GluR-B (P19491, flop isoform) (Sommer et al., 1990), were made in an analogous manner by using PCR primers encoding the tags. The C-terminal deletion fragments of GluR-B were created by PCR and used to replace the native region in the wild-type GluR-B construct. Complementary DNA clones encoding rat $4.1 \mathrm{~N}$ and $4.1 \mathrm{~B}$ were obtained from Dr. Hisashi Yamakawa (Kazusa DNA Research Institute, Chiba, Japan) (Yamakawa et al., 1999; Yamakawa and Ohara, 2000). The rat 4.1N cDNA (encoding residues 1-879) (Yamakawa and Ohara, 2000) was cloned into a derivative of pcDNA3.1 (-) (Invitrogen, San Diego, CA) that carried an N-terminal Myc-tag epitope. Complementary DNAs encoding the C-terminal domains of 4.1B (residues 965-1105; SWISS-PROT Q9JMB3) and 4.1N (734-879; Q9WTP0) were cloned by PCR using the corresponding full-length clones as templates, whereas cDNAs encoding the CTDs of 4.1R (729-858; P48193) and 4.1G (876-1005; O43491) were produced by reverse transcriptase (RT)-PCR from mRNA prepared from rat brain and HEK293 cells, respectively. The PCR fragments coding for the 4.1 CTDs were cloned into the pcDNA3.1 derivative carrying the N-terminal Myc tag. Glutathione S-transferase (GST) fusion proteins of the C-terminal region of GluR-A (residues 827-907; P19490) or GluR-D (835-902 or 849-902) were constructed by PCR and subcloned into the pGEX4-T3 vector (Amersham Biosciences, Arlington Heights, IL). The correctness of all constructs was verified by restriction enzyme digestions and by sequencing all PCR-amplified regions.

Cell culture and transfection. HEK293 cells were cultured in DMEM supplemented with $10 \%$ fetal calf serum and $2 \mathrm{~mm}$ L-glutamine and $1 \%$ penicillin-streptomycin solution. Immediately before transfection the cells were replated at a density of $2 \times 10^{5}$ cells per milliliter into T75 flasks or onto poly-D-lysine-coated coverslips for immunofluorescence. Cells were transfected using the calcium phosphate method ( $2 \mu \mathrm{g}$ plasmid DNA per $35 \mathrm{~mm}$ dish or $10 \mu \mathrm{g}$ per T75 flask) (Gorman et al., 1990). The media was changed the following day, and the cells were used for experiments $40-48 \mathrm{hr}$ after transfection.

Neuronal cultures. Rat embryonic day 18 hippocampal neurons were plated on poly-D-lysine-coated and Matrigel-coated (Becton Dickinson Labware, Mountain View, CA) coverslips at a density of $2 \times 10^{5}$ cells per milliliter and maintained in Neurobasal media supplemented with B-27 (Invitrogen) for $4 \mathrm{~d}$. Neurons were cotransfected with the GluR-D constructs and pEGFP-C1 (Clontech, Cambridge, UK) by the calcium phosphate method and examined $72 \mathrm{hr}$ after transfection.

Immunofluorescence staining. Transfected cells were fixed in 3\% paraformaldehyde and used for immunostaining directly (nonpermeabilized conditions; surface staining) or after a 25 min incubation in $0.05 \%$ Triton X-100 in PBS (permeabilized conditions; total staining). Nonspecific binding was blocked by incubation in $3 \%$ goat serum. Cells were labeled with monoclonal M1 anti-Flag IgG (Sigma, St. Louis, MO; $5 \mu \mathrm{g} / \mathrm{ml}$ ) followed by Cy3-conjugated anti-mouse IgG secondary antibody (The Jackson ImmunoResearch, West Grove, PA; $7 \mu \mathrm{g} / \mathrm{ml}$ ). Cells were examined using an Olympus Provis AX70 epifluorescence microscope. Pic- tures were collected by a Photometrics SenSys air-cooled CCD camera and Image ProPlus software.

ELISA assay. Transfected HEK293 cells were plated in poly-D-lysinecoated 24-well plates at a density of $1 \times 10^{5}$ cells per well. The cells were fixed and blocked to prevent nonspecific binding as described above. Cells were labeled with the GluR- $\mathrm{D}_{\mathrm{X}}$ antisera (1:1000 dilution; see below) followed by alkaline phosphatase-conjugated anti-rabbit IgG secondary antibody (Bio-Rad, Hercules, CA; 1:1000 dilution). Antibody labeling was detected by incubation with $p$-nitrophenyl phosphate substrate (Sig$\mathrm{ma}$ ), and absorbance was measured at $405 \mathrm{~nm}$ on a Titertek plate reader.

Antibody production. The antisera against the conserved C-terminal domain of 4.1 proteins (Hoover and Bryant, 2000) and against the $\mathrm{N}$-terminal domain of GluR-D were generated by immunizing New Zealand White rabbits with a purified His-tagged GST fusion protein of the residues 955-1005 of human 4.1G (SwissProt O43491) or with a purified His-tagged GluR-D N-terminal domain (GluR-D $\mathrm{D}_{\mathrm{X}}$; residues 22-402) (Kuusinen et al., 1999). Immunization and the collection of the sera were performed according to standard protocols (Harlow and Lane, 1988) in the Animal Facility of the Viikki Biocenter, University of Helsinki. The GluR-B/D-selective monoclonal antibody Fab7 has been described previously (Jespersen et al., 2000).

Immunoprecipitation and GST pull down. Cerebella from adult male Wistar rats were homogenized in buffer containing (in $\mathrm{mM}$ ): 50 Tris$\mathrm{HCl}$, pH 8.0, 1 EDTA, 1 EGTA, $1 \mathrm{NaF}, 1 \mathrm{Na}_{3} \mathrm{VO}_{4}, 0.5$ PMSF) ( $1 \mathrm{ml}$ per $200 \mathrm{mg}$ of tissue). Triton X-100 was then added to a final concentration of $1 \%(\mathrm{w} / \mathrm{v})$. The homogenate was mixed at $4^{\circ} \mathrm{C}$ for $2 \mathrm{hr}$, followed by ultracentrifugation at $100,000 \times g$ for $1 \mathrm{hr}$ at $4^{\circ} \mathrm{C}$, and the supernatant was collected. Transfected HEK293 cells were lysed in TNE buffer $(1 \%$ Triton X-100, 0.5\% Nonidet P-40, 50 mm Tris-HCl, pH 7.4, $120 \mathrm{~mm}$ $\mathrm{NaCl}$, 3.0 mм EDTA, $1.0 \mathrm{~mm} \mathrm{NaF}, 1.0 \mathrm{~mm} \mathrm{Na}_{3} \mathrm{VO}_{4}, 1.0 \mathrm{~mm}$ PMSF, 10 $\mu \mathrm{g} / \mathrm{ml}$ each of apoprotinin and leupeptin) and centrifuged at 13,000 rpm for $15 \mathrm{~min}$ at $4^{\circ} \mathrm{C}$ in a microfuge. Supernatants containing the rat cerebellar and HEK293 cell detergent extracts were precleared by incubating with Gamma Bind G Sepharose (Amersham Biosciences) for $2 \mathrm{hr}$ at $4^{\circ} \mathrm{C}$ and then used for immunoprecipitation or GST pull-down assay.

GST fusion proteins were expressed from pGEX3-T4 vectors in Escherichia coli BL21 according to the manufacturer's instructions (Amersham Biosciences). Bacteria were resuspended in PBS buffer containing protease inhibitors (1.0 mM PMSF, $10 \mu \mathrm{g} / \mathrm{ml}$ each of apoprotinin and leupeptin) and gently sonicated. The supernatant was incubated with 1 $\mathrm{ml}$ Glutathione-Sepharose (Amersham Biosciences) at $4^{\circ} \mathrm{C}$ for $1-2 \mathrm{hr}$, and the resins were washed extensively with PBS buffer. GST fusion proteins were eluted by $15 \mathrm{~mm}$ glutathione.

For GST pull-down assay, the supernatants were incubated with GST fusion proteins ( $1 \mathrm{ml}$ supernatant per $20 \mu \mathrm{l}$ gel containing $10 \mu \mathrm{g}$ of fusion protein) conjugated to Glutathione-Sepharose beads (Amersham Biosciences) overnight at $4^{\circ} \mathrm{C}$. For immunoprecipitation, extract was incubated with the appropriate antibody or antisera $\left(\right.$ GluR-D $\mathrm{D}_{\mathrm{TAL}} 4 \mu \mathrm{l}$; GluR-D $2 \mu \mathrm{l} ; 4.1_{\text {PAN }} 2 \mu \mathrm{l} ; 4.1 \mathrm{~N} 4 \mu \mathrm{l}$ per $500 \mu$ l extract) overnight at $4^{\circ} \mathrm{C}$ and then with Gamma Bind G Sepharose for $2 \mathrm{hr}$. For both methods the Sepharose beads were harvested by centrifugation at $3000 \mathrm{rpm}$ for $2 \mathrm{~min}$ at $4^{\circ} \mathrm{C}$ in a microfuge and washed. The bound proteins were eluted in SDS sample buffer.

Immunoblotting. Immunoblotting was done by standard protocols. Transfected cells were dissolved directly in SDS gel sample buffer $(2 \%$ SDS, 50 mm Tris-HCl, pH 7.5, 25 mm dithiothreitol, 5\% glycerol, bromophenol blue) and heated at $95^{\circ} \mathrm{C}$ for $5 \mathrm{~min}$ before loading to SDSPAGE. Polyvinylidene difluoride (PVDF) membranes were blocked overnight in 3\% milk/TBS-Tween. The anti-Flag M1 monoclonal antibody was used at $2 \mu \mathrm{g} / \mathrm{ml}$ in the presence of $1 \mathrm{mM} \mathrm{Ca}^{2+}$ per the manufacturer's recommendations. The monoclonal anti-Myc (clone 9E10) (Evan et al., 1985) was used at $3 \mu \mathrm{g} / \mathrm{ml}$. The rabbit anti-GluR-D $\mathrm{D}_{\mathrm{TAIL}}$ (Chemicon, Temecula, CA) was used at $0.5 \mu \mathrm{g} / \mathrm{ml}$. The rabbit $4.1 \mathrm{~N}$ antibody raised against residues $570-768$ of human $4.1 \mathrm{~N}$ (Scott et al., 2001) was used at $0.2 \mu \mathrm{g} / \mathrm{ml}$. The rabbit $4.1_{\text {PAN }}$ antisera was used at a dilution of 1:2000. The rabbit GluR- $D_{\mathrm{X}}$ antisera was used at a dilution of 1:2000; in immunoblots this antibody recognizes recombinant GluR-D but not GluR-A, GluR-B, or GluR-C. The secondary antibodies used were antimouse or anti-rabbit conjugated to horseradish peroxidase (HRP) (Am- 
A

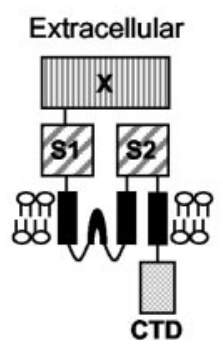

Intracellular
B

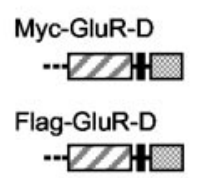

Flag-GluR-D $\Delta 837-902$ --ZZ1

Flag-GluR-D $\Delta 841-896$
$\cdots Z$ - 2 HWd

Flag-GluR-D $\Delta 849-902$ - CZ1H

Flag-GluR-D $\Delta 897-902$ - QZV

\section{Flag-GluR-D-His - S2 M4CTD}

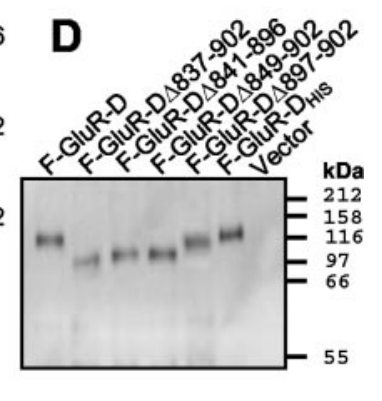

Figure 1. Expression of GluR-D C-terminal deletions in HEK293 cells. A, Topology of AMPA receptor subunits. The $X$ domain and ligand binding (S1 and S2) domains are extracellular; there are four membrane-associated regions and an intracellular C domain (CTD). B, Outline of the $C$-terminal part of the constructs. S2, Part of the ligand binding domain; $M 4$, final membrane domain; CTD, C-terminal domain; His, $6 \times$ His peptide. C, Anti-GluR-D $D_{\text {TAlL }}$ (Chemicon) immunoblot of full-length GluR-D constructs expressed in HEK293 cells, Flag-tagged GluR-D, Myctagged GluR-D, and nontagged GluR-D.D, Anti-Flag immunoblot of full-length GluR-D polypeptides and deletion mutants expressed in HEK293 cells. Vector refers to HEK293 cells transfected with the mammalian expression vector pcDNA3.1(-).

ersham Biosciences; 1:5000). The antibody labeling was detected using ECL Plus reagents (Amersham Biosciences).

\section{Results}

Expression of GluR-D and C-terminal mutants in

HEK293 cells

Homomeric GluR-D receptors were expressed in transfected HEK293 cells as nontagged wild-type receptors or as carrying either Flag or Myc tags inserted between the signal peptide cleavage site and the first residue of the mature polypeptide. The presence of these $\mathrm{N}$-terminal tags had no effect on the expression or distribution of GluR-D as determined by immunoblotting (Fig. $1 C$ ) and immunofluorescence staining (Fig. $2 A$, panels $A-F$ ). For all three constructs, transfected cells showed a strong presence of GluR-D intracellularly and clear expression of the receptor on the cell surface (Fig. 2A, panels $A-F$ ). Therefore, for convenience of detection, all further GluR-D constructs were prepared with an N-terminal Flag tag (F-GluR-D).

To determine whether the cytoplasmic C-terminal region of GluR-D (residues 837-902) is necessary for the transport and expression of the receptor on cell surface and to identify the critical structures involved, a series of C-terminal mutant constructs were prepared and expressed in transiently transfected HEK293 cells (Fig. 1 B). A single band could be detected for each mutant in immunoblotting (Fig. 1D); the bands had a slightly higher relative molecular weight than would be predicted from the core protein sequence, consistent with glycosylation of the respective polypeptides.

Immunofluorescence staining of Triton X-100-permeabilized GluR-D-expressing HEK293 cells gave bright, diffuse staining throughout the cytoplasm for all the constructs. Frequently, a more intense area of staining adjacent to the nucleus was seen (Fig. 2A), presumably attributable to accumulation in the Golgi
A
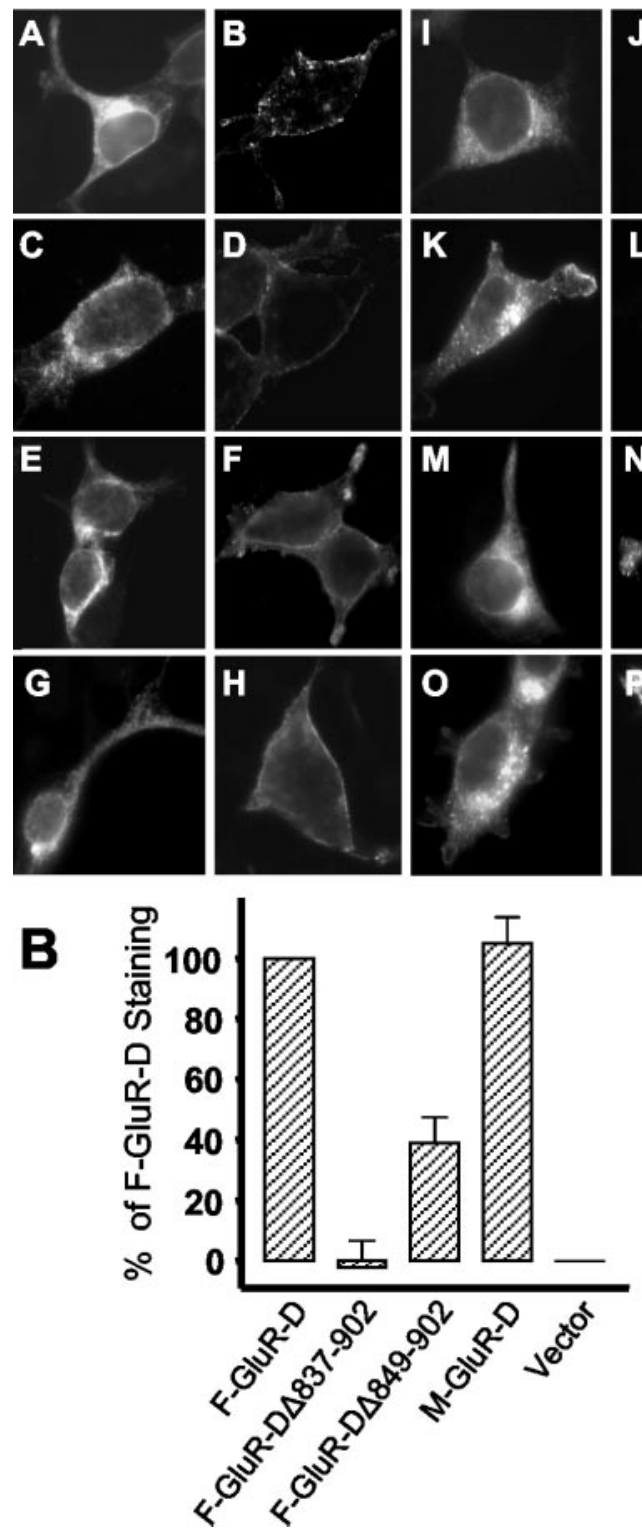
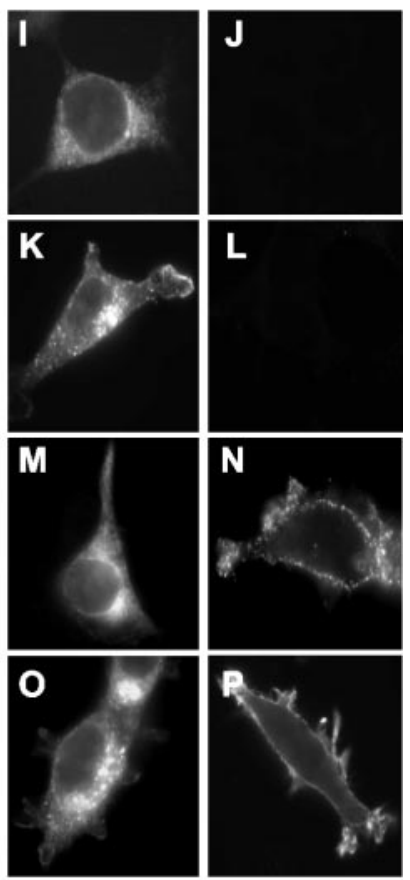

Figure 2. Surface expression in transfected HEK293 cells. $A$, Immunostaining of GluR-D constructs after transfection of HEK293 cells; $A, B$, nontagged GluR-D; C, D, Flag-GluR-D; E, F, MycGluR-D; G, H, GluR-D-His; I, J, GluR-D $\Delta 837-902 ;$ K, L, GluR-D $\Delta 841-897 ;$, M, N, GluR-D $\Delta 849$ 902; $O, P$, GluR-D $\Delta 897-902$. $A$ and $B$ were probed with Fab $7 \mathrm{lgG} ; E$ and $F$ were probed with anti-Myc lgG; $C, D, G-P$ were probed with anti-Flag lgG. Permeable staining is shown in pane/s $A, C, E, G, I, K, M$, and $O$. Nonpermeabilized expression is shown in panels $B, D, F, H, J, L, N$, and $P$. $B$, Quantitation of the degree of cell-surface expression of the GluR-D deletion mutants by ELISA. The $y$-axis indicates the level of surface expression as a percentage of the full-length, Flagtagged GluR-D construct. The values were calculated from the $\mathrm{A}_{405}$ readings (see Materials and Methods). Four separate transfections were done of all the constructs in parallel. The values were corrected for nonspecific labeling.

complex. In contrast, anti-Flag immunofluorescence staining of nonpermeabilized cells, as an indicator of the presence of the receptor on cell surface, showed striking differences between the various constructs. A complete $(\Delta 837-902)$ or near-complete ( $\Delta 841-896)$ deletion of C-terminal domain resulted in a total loss of cell surface expressed protein (Fig. $2 A$, panels $J, L$ ). In contrast, modifications at the extreme $\mathrm{C}$ terminus, either by addition of a C-terminal His tag (F-GluR-D $\left.\mathrm{D}_{\mathrm{HIS}}\right)$ or deletion of the 
last six residues (F-GluR-D $\Delta 897-902$ ), appeared to have no effect on the degree of cell surface expression of the receptor as compared with the GluR-D construct with wild-type $\mathrm{C}$ terminus (Fig. $2 A$, panels $H, P)$. Interestingly, deletion of the last 54 residues $(\Delta 849-902)$ yielded clear immunoreactivity on cell surface (Fig. $2 A$, panel $N)$, indicating that a cytoplasmic segment of only 14 residues (835-848) following the M4 membrane-associated segment is minimally required for localizing GluR-D on the surface of transfected HEK293 cells. To complement these qualitative results, we used an ELISA-type assay to determine the binding of a polyclonal antibody specific for the N-terminal domain of GluR-D to fixed, nonpermeabilized cells expressing C-terminal mutants. Consistent with immunofluorescence results, removal of the entire C domain $(\Delta 837-902)$ reduced the signal to background levels obtained from cells transfected with the empty expression vector, whereas the construct maintaining the 14 M4 proximal residues produced a signal of $\sim 40 \%$ of that of the "wild-type" control (F-GluR-D) (Fig. 2 B). Parallel transfections with the Myc-tagged full-length subunit (M-GluR-D) produced an equally strong signal as F-GluR-D construct (Fig. $2 \mathrm{~B}$ ), showing that the identity of the N-terminal tag has no effect on the expression and localization of GluR-D and that the technique is a reliable measure.

\section{Role of the C-terminal domain in the surface expression of GluR-B}

To examine whether the drastic differences in the cellular localization of the deletion mutants F-GluR-D $\Delta 849-902$ and GluRD $\Delta 837-902$ were unique for the GluR-D subunit or more general, the equivalent constructs were made for the GluR-B subunit. The three constructs, F-GluR-B, F-GluR-B $\Delta 837-883$, and F-GluR-B $\Delta 848-883$, were expressed at similar levels in HEK293 cells as indicated by anti-Flag immunoblots (Fig. $3 A$ ) or by immunofluorescence staining of permeabilized cells (Fig. $3 B$, panels $A, C, E)$. In nonpermeabilized cells, full-length F-GluR-B and FGluR-B $\Delta 848-883$ were clearly present on the cell surface (Fig. $3 \mathrm{~B}$, panels $B, D)$, although the latter appeared somewhat less abundant. However, F-GluR-B $\Delta 837-883$ lacking the entire CTD was not detectable at all in nonpermeabilized cells (Fig. $3 B$, panel $F$ ). These results indicate that for both GluR-B and GluR-D, the $\mathrm{C}$-terminal domain is necessary for the surface expression. Moreover, the M4 proximal 14 residue segment, which is identical to that of GluR-D, is sufficient to localize homomeric GluR-B receptors to the cell surface in HEK293 cells.

\section{Point mutations of the M4 proximal region}

To further analyze the role of the M4 proximal segment in either guiding the GluR-D to the cell surface or in stabilizing the receptor already on the surface, a series of point mutations were made within this region (Fig. $4 A$ ). Immunoblotting indicated that five different single residue mutants, C837S, Y838F, R841S, K845S, and R846S, and the triple mutation R841S/K845S/R846S were expressed at the same level as the Flag-tagged wild-type GluR-D (Fig. $4 B$ ). Moreover, all of the point mutants gave clear and intense staining in permeabilized cells (Fig. 4C) (data not shown). However, clear differences were observed in the nonpermeabilized immunostaining, both in microscopy and in ELISA. The mutants C837S, Y838F, and R846S were present on the cell surface at the same level as F-GluR-D (Fig. 4C,D) (data not shown), whereas the mutants R841S and K845S were present at a slightly, but consistently, lower level than the wild-type receptor $(81 \%$ and 69\%, respectively) (Fig. 4D). The triple mutation (R841S/ K845S/R846S) in which three positively charged side-chains were

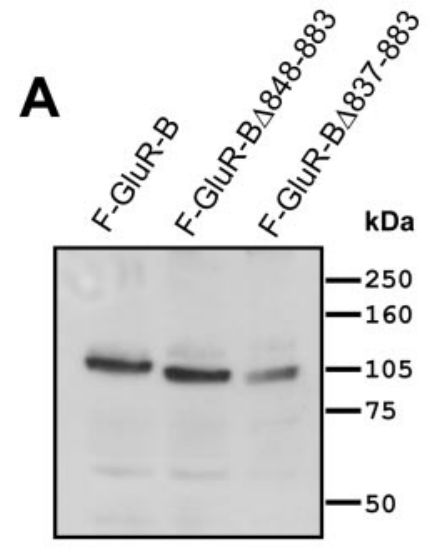

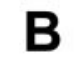
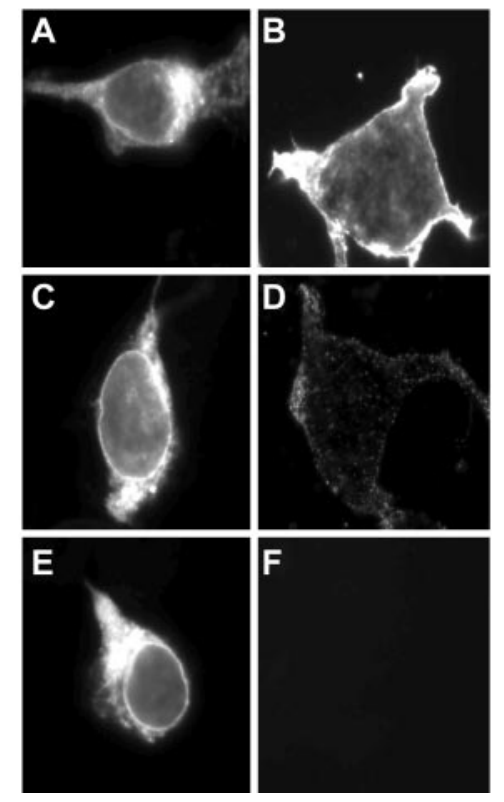

Figure 3. Role of the M4 proximal region for surface expression of GluR-B. A, Anti-Flag immunoblot of full-length and mutant Flag-tagged GluR-B constructs expressed in HEK293 cells. $B$, Immunofluorescence staining of $N$ terminally Flag-tagged GluR-B constructs after expression in HEK293 cells. Panels A, B, GluR-B; C, D, GluR-B $\Delta 848-883 ; E$, F, GluR-B $\Delta 837-883$. All cells were immunostained with anti-Flag $\lg G$. Panels $A, C$, and $E$ represent permeabilized cells; panels $B, D$, and $F$ represent nonpermeabilized cells.

neutralized had a significantly reduced $(28 \pm 4 \%)$ cell surface expression level as compared with the wild-type protein (Fig. $4 C, D)$, indicating that the participation of the 14-residue segment in the mechanisms that contribute to the surface localization of GluR-D is dependent on its exact amino acid sequence.

\section{Neuronal localization of deletion mutants}

All of the studies described above were performed in HEK293 cells, which are of non-neuronal origin and do not normally express glutamate receptors. Therefore, it was important to determine whether the expression of GluR-D on the cell surface would have a similar requirement for the 14-residue M4 proximal region in neuronal cells. To test this possibility, hippocampal E18 primary cultures were cotransfected with expression plasmids for green fluorescent protein (GFP) (to help identify transfected cells) and F-GluR-D, F-GluR-D $\Delta 849-902$, or F-GluR-D $\Delta 837-902$ and then stained with anti-Flag IgG. Flag immunoreactivity was seen for all three constructs in perme- 


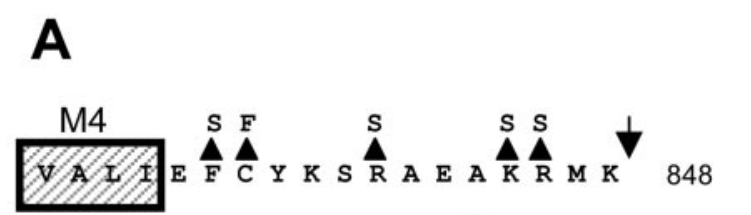

I T F S E A T R N K A R LSSI T G S 866

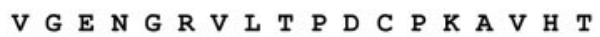

G T A I R Q S S G L V I A S D L P

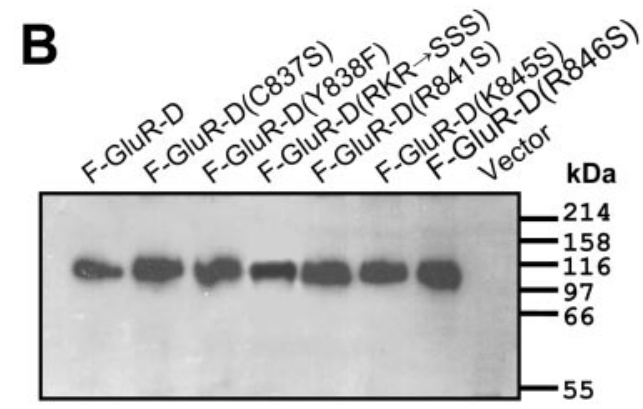

C
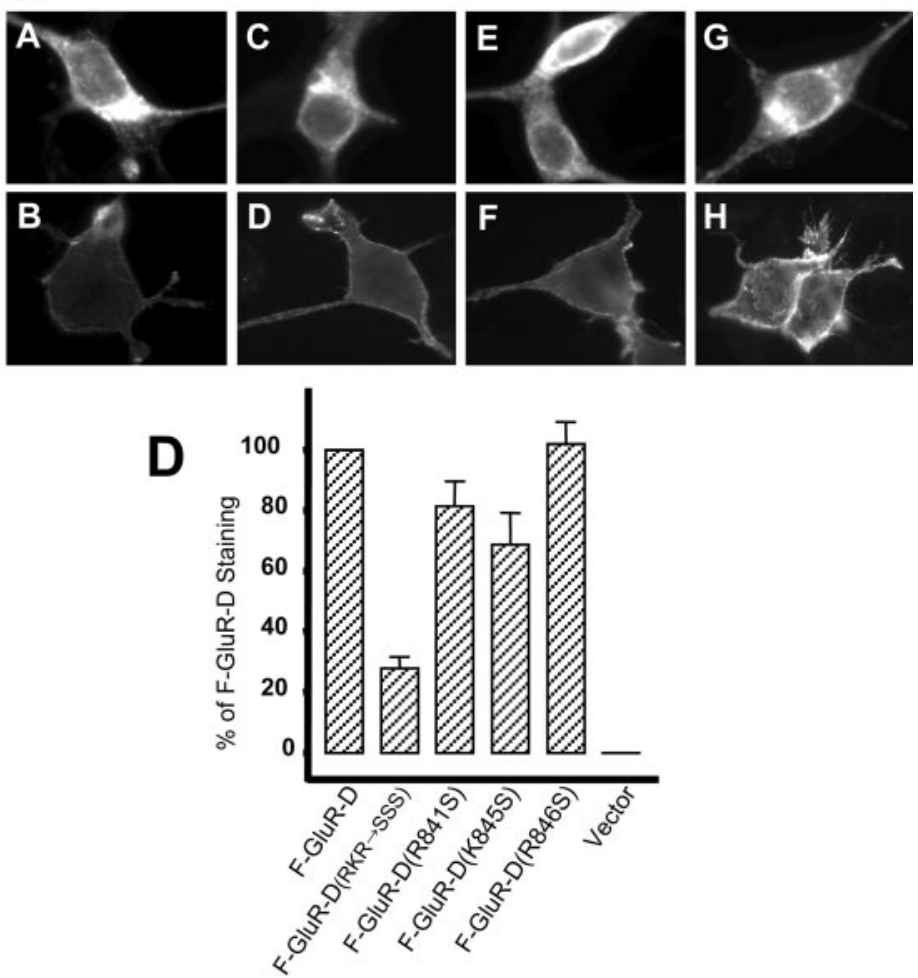

Figure 4. Point mutations of the M4 proximal region. $A$, Sequence of the GluR-D CTD indicating the positions of the point mutations (arrowhead); residue numbers are given on the right. The arrow indicates the junction between the alternative ( termini of GluR-D. Only the major form is shown. The serine residue identified previously as a target for PKA (Carvalho et al., 1999) is circled. $B$, Anti-Flag immunoblot of GluR-D point mutation constructs expressed in HEK293 cells. Vector refers to cells transfected with an empty expression vector (pcDNA3.1). C, Immunofluorescence staining of GluR-D constructs after expression in HEK293 cells. Panels A, B, GluR-D (R841S, K845S, R846S); C, D, GluR-D(R841S); E, F, GluR-D(K845S); G, H, GluR-D(R846S). Panels A, C, E, and F show permeable staining, whereas $B, D, F$, and $H$ show nonpermeabilized staining. All cells were immunostained with anti-Flag lgG. $D, Q$ uantitation of the degree of cell-surface expression of the GluR-D point mutants by ELISA. The $y$-axis indicates the level of surface expression as a percentage of the full-length, Flag-tagged GluR-D construct.

abilized transfected cells that also displayed GFP fluorescence (data not shown). In contrast, only F-GluR-D and F-GluR$\mathrm{D} \Delta 849-902$, which contains the 14-residue segment, were detected on the cell membrane in nonpermeabilized neurons (Fig. $5 B, D)$. Because the immature neurons were not maintained in culture long enough for synaptogenesis, synaptic localization of the expressed proteins could not be examined. The above results are consistent with the results obtained from HEK293 cells and suggest that the 14-residue segment is also essential for the surface expression of GluR-D in neurons.

\section{Interaction of GluR-D with 4.1 family proteins in HEK293 cells}

A recent report demonstrated a direct interaction between the GluR-A AMPA receptor subunit and members of the 4.1 protein family in the yeast two-hybrid system (Shen et al., 2000). Interestingly, this interaction was shown to have a minimal requirement for a 14-residue segment in GluR-A similar (two amino acid differences) to the one that we identified in GluR-D and to have an influence on the surface expression of GluR-A in HEK293 cells. Thus, it was clearly relevant to examine the possibility that interaction with 4.1 proteins may be involved in the transport of GluR-D to the cell surface in HEK293 cells.

First, we confirmed the presence of a widely expressed member of the 4.1 family, 4.1G, in HEK 293 cells by RT-PCR (data not shown) and prepared an antiserum against the C-terminal domain of this protein (Fig. 6A). The sequences of the CTDs of 4.1 proteins are relatively conserved; in pairwise comparisons, $4.1 \mathrm{G}$,
4.1B, and 4.1R have $71-73 \%$ sequence identity, whereas the CTD of $4.1 \mathrm{~N}$ is somewhat more distant, sharing $46-49 \%$ identity with the other three paralogs. Indeed, in immunoblots of transfected HEK293 cells expressing Myc-tagged CTDs of 4.1N, 4.1B, 4.1G, and $4.1 \mathrm{R}$, the antiserum recognized all four CTDs, although the comparison between the relative intensities of the immunoreactive bands produced by this " $4.1_{\text {PAN }}$ " antiserum and by anti-Myc antibody indicated that the antiserum reacts most strongly with the CTDs of $4.1 \mathrm{G}$ and 4.1B (Fig. $6 \mathrm{~B}$ ). The antiserum specifically recognized a strong $\sim 160 \mathrm{kDa}$ band in HEK293 cells, consistent with the electrophoretic size of the major isoforms of 4.1G (Yamakawa and Ohara, 2000), and weaker bands of 100, 75, and 50 $\mathrm{kDa}$, which were variably present (Fig. $6 C$ ). To confirm the identity of the $\sim 160 \mathrm{kDa}$ band, the antibody incubations for the immunoblots were performed in the presence of GST-fused CTDs of $4.1 \mathrm{~N}, 4.1 \mathrm{~B}$, and $4.1 \mathrm{G}$. The immunoreactivity of the $\sim 160 \mathrm{kDa}$ band was abolished totally by the presence of $4.1 \mathrm{G}-$ CTD, but was less influenced by comparable amounts of CTDs of $4.1 \mathrm{~N}$ and 4.1B (Fig. 6C). The intensities of the minor bands were also diminished in the presence of an excess of soluble CTDs, suggesting that they may also represent isoforms or degradation products of 4.1 family proteins.

To examine the cellular localization of the endogenously expressed 4.1 protein(s), nontransfected HEK293 cells were permeabilized by Triton X-100 and stained with the 4.1 antisera and the corresponding preimmune serum. Although the staining was generally weak, it appeared to be specific because no staining was observed with the preimmune serum (Fig. 6D). Interestingly, 

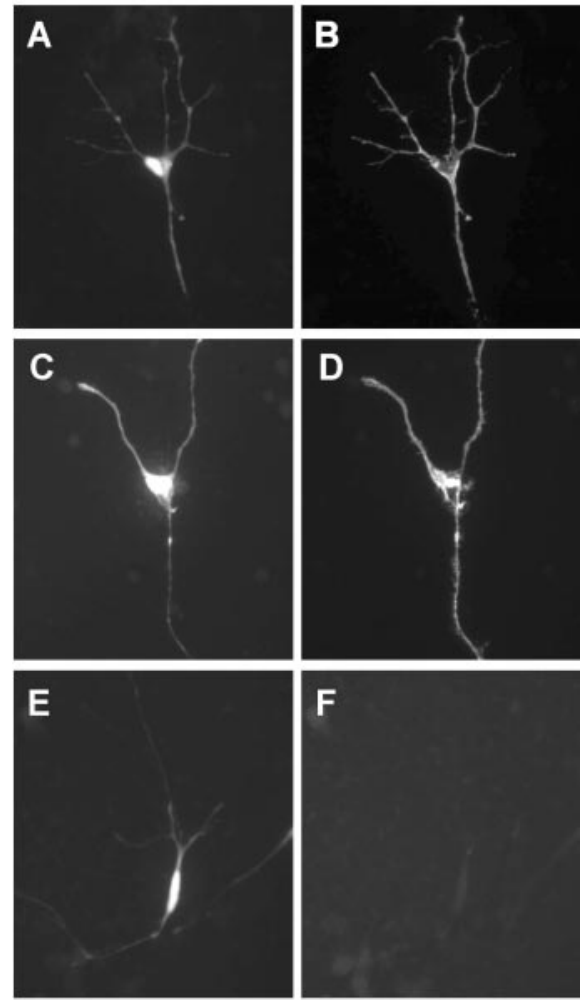

Figure 5. Importance of GluR-D CTD for cellular localization in neurons. Immunostaining of hippocampal neurons after cotransfection of EGFP and GluR-D constructs: $A, B$, GluR-D; $C, D$, GluR-D $\Delta 849-902 ; E, F$, GluR-D $\Delta 837-902$. EGFP fluorescence is shown in $A, C$, and $E$. Nonpermeabilized anti-Flag IgG immunostaining is shown in $B, D$, and $F$.

more intense labeling was seen corresponding to the cell plasma membrane and, possibly, to the nuclear membrane (Fig. $6 D$ ).

The previous data showed that HEK293 cells express at least one member of the 4.1 protein family. Thus, it was important to determine whether the GluR-D could associate with endogenously expressed 4.1 proteins in the HEK293 cells and whether the M4 proximal segment plays any role in this association. As shown in Figure $6 D$, the $4.1_{\mathrm{PAN}}$ antiserum coprecipitated the transiently expressed F-GluR-D from HEK cell extracts. However, F-GluR-D(RKR-SSS), which carries three point mutations in the 14-residue segment and has a significantly reduced surface expression, did not coimmunoprecipitate with 4.1, although it was expressed at a similar or even slightly higher level than the wild-type F-GluR-D (Fig. 6E). These results indicate that GluR-D is associated with endogenously expressed 4.1 protein(s) in HEK293 cells, and this association is affected by mutations within the 14-residue segment.

\section{In vivo and in vitro interaction between GluR-D and $4.1 \mathrm{~N}$}

The possible interaction of GluR-D with 4.1 family proteins in vivo was examined by immunoprecipitation from rat cerebellum, a rich source of GluR-D. Two different GluR-D-specific antibodies were used: a GluR-D-specific antiserum prepared against the $\mathrm{N}$-terminal domain and a commercial affinity-purified antibody against a C-terminal peptide. The $4.1_{\mathrm{PAN}}$ antiserum characterized above, but not the corresponding preimmune serum, precipitated GluR-D as detected by both antibodies from rat cerebellar detergent extract (Fig. 7A). GluR-D immunoreactivity was also present in immunoprecipitates produced by using a $4.1 \mathrm{~N}$-specific affinity-purified antibody (Scott et al., 2001) instead of 4.1 $1_{\text {PAN }}$.
A

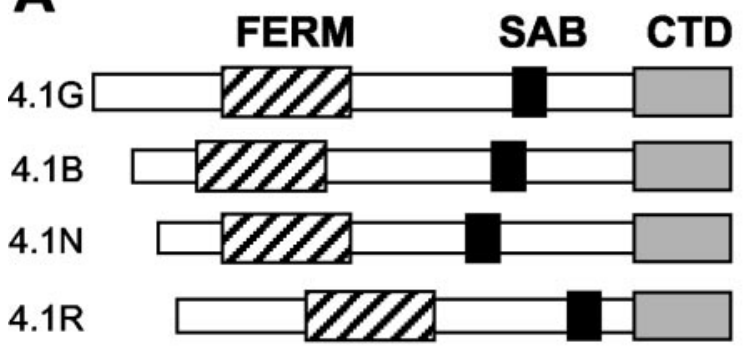

$73 \%$

$46 \%$

$71 \%$

B
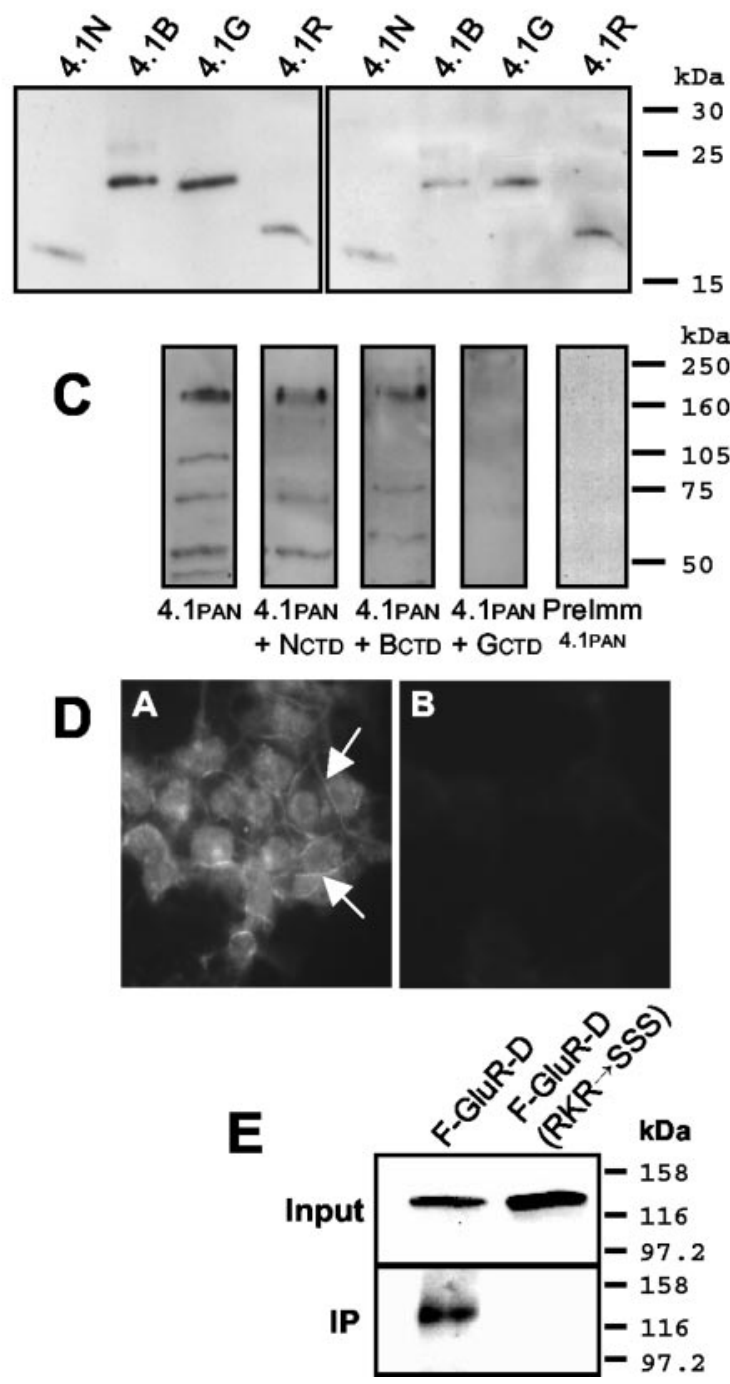

Figure 6. Interaction of GluR-D and 4.1 proteins in HEK293 cells. A, Schematic of the 4.1 protein isoforms. The 4.1-ezrin-radixin-moesin (FERM) domain, spectrin/actin binding (SAB) domain, and C-terminal domain (CTD) are indicated. The homology of the 4.1G CTD region used to generate the $4.1_{\text {PAN }}$ antiserum to the $4.1 B, 4.1 \mathrm{~N}$, and $4.1 R$ CTDs is indicated. $B$, Immunoblots of the CTDs of the 4.1 proteins $(N, B, G$, and $R$ ) immunoprecipitated from transfected HEK293 cells via an N-terminally fused Myc-tag. The left-hand panel was probed with the $4.1_{\text {PAN }}$ antiserum, whereas the right-hand panel was probed with anti-Myc lgG. C, Immunoblots of untransfected HEK293 cells showing the presence of 4.1 family members. The panels were probed with the 4.1 $1_{\text {PAN }}$ antiserum with or without preincubation with the indicated 4.1 CTD protein. The extreme right-hand panel was probed with the corresponding preimmune serum. D, Untransfected HEK293 cells stained with the $4.1_{\text {PAN }}$ antiserum ( panel A) or with the preimmune serum ( panel $B$ ). Arrows indicate the more intense staining outlining the plasma membrane. $E$, HEK293 cells expressing either F-GluR-D or F-GluR-D(RKR-SSS) were immunoprecipitated with 4. $1_{\text {PAN }}$ antiserum. The top panel is a direct anti-GluR- $D_{X}$ immunoblot of the cell lysates, whereas the bottom panel represents the anti-4. $1_{\text {PAN }}$ immunoprecipitate. 


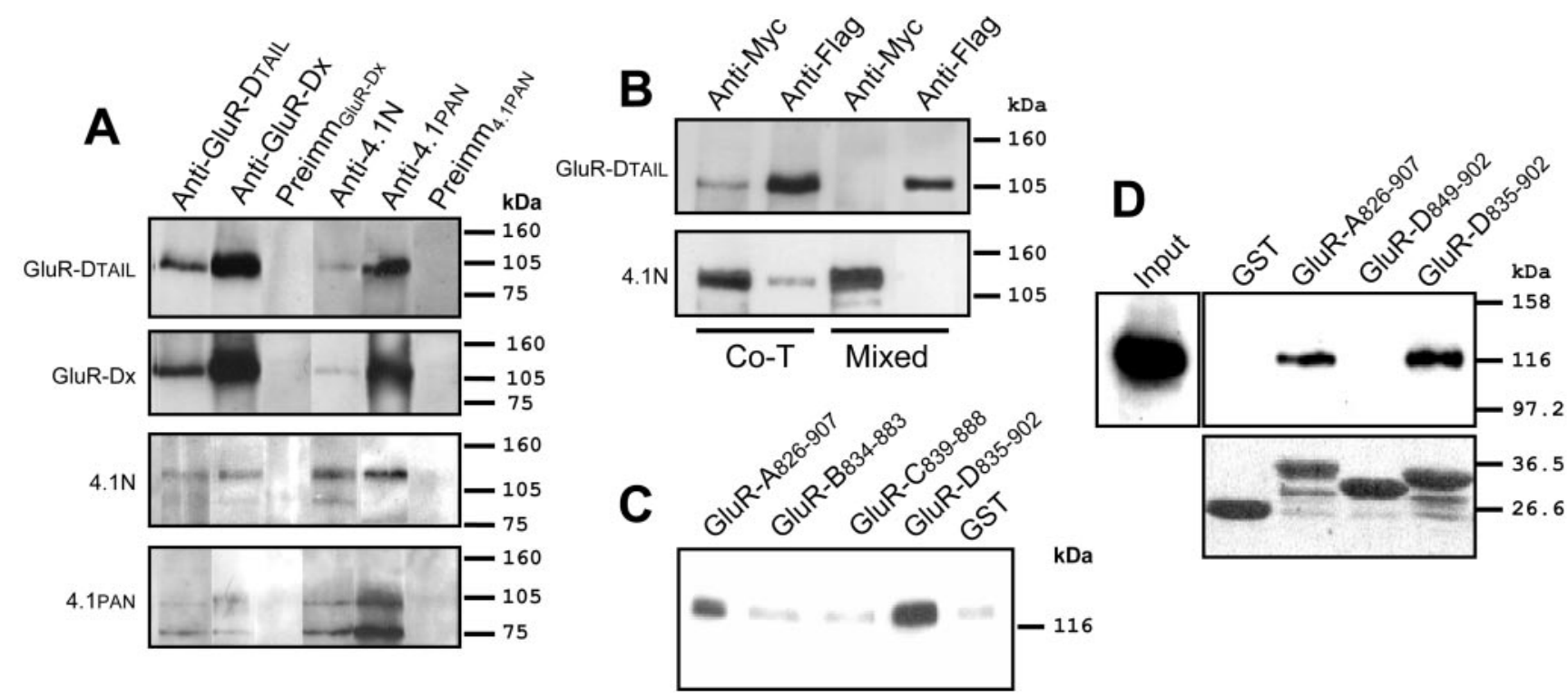

Figure 7. In vivo and in vitro interactions between GluR-D and 4.1N. A, In vivo interaction of 4.1 and GluR-D-containing AMPA receptors. Rat cerebellar detergent extract was immunoprecipitated with the antisera or preimmune sera indicated above. Immunoblots were probed with the antisera indicated to the left, followed by anti-rabbit lgG conjugated to HRP. B, HEK293 cells were either cotransfected with F-GluR-D and Myc-4.1N (Co-T) expression vectors or singly transfected with the constructs; the latter were mixed during solubilization and immunoprecipitation (Mixed). The extracts were then immunoprecipitated with antibodies to the Flag and Myc tags, as indicated above. Immunoblots were probed with the antibodies indicated to the side. C, Interaction of 4.1N protein with the CTDs of GluR-A, GluR-B, GluR-C, and GluR-D. HEK293 cell extract expressing Myc-4.1N was probed by GST pull-down assay using the fusion proteins indicated above. The blot was then probed by anti-Myc lgG, followed by anti-mouse lgG-HRP. The bands seen with the GluR-B and GluR-C GST fusion proteins correspond to background levels seen with GST alone. D, The interaction of 4.1N with GluR-D requires the M4 proximal region. The Input panel shows the expression of Myc-tagged 4.1N in the lysate of transfected HEK293 cells. The right-hand panel shows the precipitation of the expressed Myc-4.1N by the GST fusion proteins indicated above. Both panels were probed by anti-Myc IgG, followed by anti-mouse IgG-HRP. The bottom panel shows Ponceau S staining of the expressed GST fusion proteins used in the pull-down assay.

Conversely, a $4.1 \mathrm{~N}$-immunoreactive $120 \mathrm{kDa}$ species, corresponding to the major $4.1 \mathrm{~N}$ isoform in the brain (Scott et al., 2001), was present in GluR-D immunoprecipitates but not in preimmune controls. Interestingly, although the $4.1_{\mathrm{PAN}}$ antiserum clearly immunoprecipitated $4.1 \mathrm{~N}$, it did not recognize the $120 \mathrm{kDa} 4.1 \mathrm{~N}$ species in the immunoprecipitates. Rather, it detected 100 and $75 \mathrm{kDa}$ species in 4.1 and GluR-D immunoprecipitates but not in controls produced by using the corresponding preimmune sera (Fig. $7 A$ ). Similarly sized $4.1_{\text {PAN }}$-immunoreactive bands were also present in HEK293 cell immunoblots (Fig. $6 \mathrm{C}$ ). Although the sizes correspond to the major isoforms of $4.1 \mathrm{R}$ and to the lower molecular weight splice variants of $4.1 \mathrm{~N}$ (Walensky et al., 1999; Yamakawa et al., 1999; Yamakawa and Ohara, 2000; Scott et al., 2001), it is not clear whether that is indeed what they are; they may be other splice variants or degradation products.

These results demonstrate that GluR-D and $4.1 \mathrm{~N}$ and possibly other 4.1 protein(s) exist in the same molecular complexes in rat brain. Next, we investigated the possibility that there is a direct bimolecular interaction between GluR-D and 4.1 protein(s). First, immunoprecipitation from HEK293 cells cotransfected with F-GluR-D and Myc-tagged 4.1N showed that the molecules associate with each other (Fig. $7 B$ ). No co-association was observed in a control experiment in which extracts from singly transfected cells were combined and then used for the immunoprecipitation (Fig. $7 B$ ), thus excluding the possibility that the co-association is an artifact of the solubilization procedure. Next, to study the interaction between $4.1 \mathrm{~N}$ and GluR-D in more detail, we analyzed the binding of full-length Myc-tagged 4.1N to CTDs of AMPA receptor subunits fused to GST by pull-down assay. In agreement with the yeast two-hybrid results of Shen and coworkers (2000), clear binding of $4.1 \mathrm{~N}$ to GluR-A CTD was observed, whereas binding to the CTDs of either GluR-B or GluR-C was no greater than the nonspecific binding seen with GST alone (Fig. 7C). Consistent with our immunoprecipitation results, a strong interaction was seen with the GluR-D CTD (Fig. 7C,D), indicating that GluR-D associates with 4.1 proteins via a direct interaction. Notably, no binding of $4.1 \mathrm{~N}$ was seen to the GluR-D CTD mutant that lacked the M4 proximal 14 residues (Fig. $7 D$ ). The presence of comparable amounts of GST fusion proteins was confirmed by Ponceau S staining of the PVDF membrane before immunoblotting (Fig. 7D, bottom panel). Overall, the GST pull downs demonstrate that the GluR-D C-terminal domain can directly bind to 4.1 protein(s) in a manner that is dependent on the presence of the 14-residue M4 proximal segment.

\section{Discussion}

In contrast to the other AMPA receptor subunits, not much is known to date about the intracellular protein interactions involving the GluR-D subunit. Although stargazin (a voltage-gated calcium channel $\gamma$-subunit homolog) has been reported to interact with all four AMPA receptor subunits and to be necessary for their transport to synapses in cerebellar granule cells, the location of its interaction site in the AMPA receptors is not known (Chen et al., 2000). In the present study, we show that GluR-D interacts with 4.1 protein(s) via its C-terminal domain both in vivo and in vitro and that this interaction is involved in the expression of GluR-D-containing AMPA receptors on the cell surface.

Our initial experiments indicated that the deletion of the entire C-terminal domain blocks the surface expression of GluR-D both in transfected HEK293 cells and in neurons. Subsequently, we found that a C-terminal 14-residue segment immediately following the M4 membrane domain is essential for surface localization of GluR-D both in HEK293 cells and in neurons. How- 
ever, quantitative ELISA measurements on transfected HEK293 cells showed that homomeric receptors carrying a truncated 14residue tail were present on the cell surface at a level of only $40 \%$ of that of the full-length receptor, indicating that the 14-residue segment alone is not completely sufficient for either the transport of the receptor to the cell surface or its subsequent stabilization at the wild-type level. Therefore, it is likely that parallel mechanisms exist that involve the more distal parts of the C-terminal domain of GluR-D to promote its expression on the surface of HEK293 cells.

While our study was in progress, Shen and coworkers (2000) reported an association between $4.1 \mathrm{~N}$ and the GluR-A AMPA receptor subunit that showed a similar dependence on the M4 proximal segment. This prompted us to examine the possibility that GluR-D may also interact with the 4.1 proteins. First, immunoprecipitation analysis showed that 4.1 protein(s) and GluR-D coexist in the same molecular complex, both in rat cerebellar extracts and in HEK293 cells expressing recombinant GluR-D. Second, a triple point mutation (R841S/K845S/R846S) that neutralized three positive charges in the 14-residue segment drastically reduced the surface expression of GluR-D in transfected HEK293 cells. Concomitantly, this mutation also knocked out the interaction with endogenous 4.1 protein(s), as detected by immunoprecipitation. Finally, in a GST pull-down assay, Myctagged $4.1 \mathrm{~N}$ bound to "full-length" C-terminal domains of GluR-D and GluR-A, but not to the GluR-D C-terminal domain, which lacked the M4 proximal segment.

The current results strongly suggest that the 14-residue segment mediates a direct interaction with 4.1 protein(s) that is essential for the expression of GluR-D on the cell surface. The sequence of this segment does not contain any known interaction motifs but is conserved in AMPA receptors (see below). In GST the pull-down assay, $4.1 \mathrm{~N}$ bound to the C-terminal domains of GluR-A and GluR-D but not to those of GluR-B and GluR-C, although the M4 proximal segments of GluR-A and GluR-D have less sequence identity (12 residues in 14) than GluR-D has with either GluR-B (no differences) or GluR-C (one difference). Thus, it is likely that binding of 4.1 involves also structural determinants located C-terminally from this segment. Interestingly, the "long" C-terminal tails of GluR-A and GluR-D have several regions of high sequence similarity beyond the 14-residue segment that are not shared by the GluR-B or GluR-C subunits. Therefore, we propose that the binding site of 4.1 protein consists of two separate regions: one corresponds to the M4 proximal area, whereas the other is formed by more distal, and as yet unidentified, structures. The latter interaction site would impart additional affinity and subunit specificity for the interaction. However, even in its absence, the residual interaction confers a partial rescue of the surface expression as seen with the truncated GluR-D and GluR-B constructs. Previously, Shen and coworkers (2000) used the yeast two-hybrid system for detailed mapping of the 4.1-GluR-A interaction. They reported that the M4 proximal 14-residue segment of GluR-A interacts with the C-terminal domain of 4.1G. The apparent discrepancy between this finding and our suggestion that 4.1 proteins bind to GluR-D CTD using two separate sites may be explained by the suggestion that GST pulldown assays are more sensitive than the yeast two-hybrid system to decreased avidity of binding when one or other of the two binding regions is eliminated.

The mechanism by which 4.1 interaction promotes expression of GluR-D on the cell surface is unclear and not necessarily identical in neurons and HEK293 cells. In principle, the amount of receptor present on the cell surface is determined by the relative rates of insertion and removal of the receptor from the plasma membrane and the stability of the receptor while on the surface. Members of the 4.1 protein family have been implicated in linking plasma membrane proteins to actin cytoskeleton, in the maintenance of cellular integrity, and in cell adhesion (for review, see Hoover and Bryant, 2000; Baines et al., 2001). Previously, the importance of polymerized actin for immobilization and clustering of AMPA receptors (Allison et al., 1998; Kim and Lisman, 1999) has been shown. Moreover, the study on the 4.1-GluR-A interaction suggested that the ability of 4.1 proteins to provide a link between GluR-A and actin filaments was important for the surface localization of GluR-A (Shen et al., 2000). All four 4.1 homologs cloned to date-4.1R (Conboy et al., 1986; Huang et al., 1993), 4.1G (Parra et al., 1998; Walensky et al., 1998), 4.1B (Parra et al., 2000; Yamakawa and Ohara, 2000), and 4.1N (Walensky et al., 1999; Yamakawa et al., 1999)—are expressed in the brain, albeit at different levels (Yamakawa and Ohara, 2000), and are present in postsynaptic density preparations (Scott et al., 2001). Our present results indicate that at least $4.1 \mathrm{~N}$ and the 4.1 protein(s) endogenously expressed in HEK293 cells can associate with GluR-D. Therefore, both GluR-A (Shen et al., 2000) and GluR-D subunits are likely to bind to the same 4.1 isoforms.

Interestingly, Malinow and coworkers (Zhu et al., 2000) have shown that during early postnatal development, spontaneous activity triggers the delivery of GluR-D-containing AMPA receptors to synapses, later to be replaced by GluR-B-containing receptors. Unlike the delivery of GluR-A-containing AMPA receptors associated with LTP, the delivery of GluR-D was independent of $\mathrm{Ca}^{2+} /$ calmodulin-dependent protein kinase (and of type I PDZ domain interaction) but dependent on protein kinase A-mediated phosphorylation (Hayashi et al., 2000; Zhu et al., $2000)$. It is interesting to note that 4.1 proteins seem to interact specifically with the two AMPA receptor subunits implicated in synaptic plasticity. Moreover, it is tempting to speculate that this interaction plays an essential role in the synaptic delivery of GluR-A and GluR-D. Additional studies focusing on the regulation of the interaction of 4.1 proteins with AMPA receptor subunits and on their involvement in synaptic plasticity are clearly warranted.

\section{References}

Allison DW, Gelfand VI, Spector I, Craig AM (1998) Role of actin in anchoring postsynaptic receptors in cultured hippocampal neurons: differential attachment of NMDA versus AMPA receptors. J Neurosci 18:2423-2436.

Baines AJ, Keating L, Phillips GW, Scott C (2001) The postsynaptic spectrin/4.1 membrane protein "accumulation machine". Cell Mol Biol Lett 6:691-702.

Bolton MM, Blanpied TA, Ehlers MD (2000) Localization and stabilization of ionotropic glutamate receptors at synapses. Cell Mol Life Sci 57:1517-1525.

Carvalho AL, Kameyama K, Huganir RL (1999) Characterization of phosphorylation sites on the glutamate receptor 4 subunit of the AMPA receptors. J Neurosci 19:4748-4754.

Chen L, Chetkovich DM, Petralia RS, Sweeney NT, Kawasaki Y, Wenthold RJ, Bredt DS, Nicoll RA (2000) Stargazin regulates synaptic targeting of AMPA receptors by two distinct mechanisms. Nature 408:936-943.

Conboy J, Kan YW, Shohet SB, Mohandas N (1986) Molecular cloning of protein 4.1, a major structural element of the human erythrocyte membrane skeleton. Proc Natl Acad Sci USA 83:9512-9516.

Dev KK, Nishimune A, Henley JM, Nakanishi S (1999) The protein kinase C alpha binding protein PICK1 interacts with short but not long form alternative splice variants of AMPA receptor subunits. Neuropharmacology 38:635-644.

Dingledine R, Borges K, Bowie D, Traynelis SF (1999) The glutamate receptor ion channels. Pharmacol Rev 51:7-61. 
Dong H, O’Brien RJ, Fung ET, Lanahan AA, Worley PF, Huganir RL (1997) GRIP: a synaptic PDZ domain-containing protein that interacts with AMPA receptors. Nature 386:279-284.

Dong H, Zhang P, Song I, Petralia RS, Liao D, Huganir RL (1999) Characterization of the glutamate receptor-interacting proteins GRIP1 and GRIP2. J Neurosci 19:6930-6941.

Evan GI, Lewis GK, Ramsay G, Bishop JM (1985) Isolation of monoclonal antibodies specific for human c-myc proto-oncogene product. Mol Cell Biol 5:3610-3616.

Gallo V, Upson LM, Hayes WP, Vyklicky L, Winters CA, Buonanno A (1992) Molecular cloning and development analysis of a new glutamate receptor subunit isoform in cerebellum. J Neurosci 12:1010-1023.

Gorman CM, Gies DR, McCray G (1990) Transient production of proteins using an adenovirus transformed cell line. DNA Prot Eng Tech 2:3-10.

Harlow E, Lane D (1988) Antibodies: a laboratory manual. Cold Spring Harbor, NY: Cold Spring Harbor Laboratory.

Hayashi Y, Shi SH, Esteban JA, Piccini A, Poncer JC, Malinow R (2000) Driving AMPA receptors into synapses by LTP and CaMKII: requirement for GluR1 and PDZ domain interaction. Science 287:2262-2267.

Hollmann M, Heinemann S (1994) Cloned glutamate receptors. Annu Rev Neurosci 17:31-108.

Hoover KB, Bryant PJ (2000) The genetics of the protein 4.1 family: organizers of the membrane and cytoskeleton. Curr Opin Cell Biol $12: 229-234$.

Huang JP, Tang CJ, Kou GH, Marchesi VT, Benz EJ, Tang TK (1993) Genomic structure of the locus encoding protein 4.1. Structural basis for complex combinational patterns of tissue-specific alternative RNA splicing. J Biol Chem 268:3758-3766.

Jespersen LK, Kuusinen A, Orellana A, Keinänen K, Engberg J (2000) Use of proteoliposomes to generate phage antibodies against native AMPA receptor. Eur J Biochem 267:1382-1389.

Keifer J (2001) In vitro eye-blink classical conditioning is NMDA receptor dependent and involves redistribution of AMPA receptor subunit GluR4. J Neurosci 21:2434-2441.

Kim CH, Lisman JE (1999) A role of actin filament in synaptic transmission and long-term potentiation. J Neurosci 19:4314-4324.

Kohler M, Kornau HC, Seeburg PH (1994) The organization of the gene for the functionally dominant alpha-amino-3-hydroxy-5-methylisoxazole-4-propionic acid receptor subunit GluR-B. J Biol Chem 269:17367-17370.

Kuusinen A, Abele R, Madden DR, Keinänen K (1999) Oligomerization and ligand-binding properties of the ectodomain of the alpha-amino-3hydroxy-5-methyl-4-isoxazole propionic acid receptor subunit GluRD. J Biol Chem 274:28937-28943.

Leonard AS, Davare MA, Horne MC, Garner CC, Hell JW (1998) SAP97 is associated with the alpha-amino-3-hydroxy-5-methylisoxazole-4propionic acid receptor GluR1 subunit. J Biol Chem 273:19518-19524.

Luscher C, Nicoll RA, Malenka RC, Muller D (2000) Synaptic plasticity and dynamic modulation of the postsynaptic membrane. Nat Neurosci 3:545-550.

Man HY, Ju W, Ahmadian G, Wang YT (2000) Intracellular trafficking of AMPA receptors in synaptic plasticity. Cell Mol Life Sci 57:1526-1534.

Nishimune A, Isaac JT, Molnar E, Noel J, Nash SR, Tagaya M, Collingridge GL, Nakanishi S, Henley JM (1998) NSF binding to GluR2 regulates synaptic transmission. Neuron 21:87-97.
Parra M, Gascard P, Walensky LD, Snyder SH, Mohandas N, Conboy JG (1998) Cloning and characterization of 4.1G (EPB41L2), a new member of the skeletal protein 4.1 (EPB41) gene family. Genomics 49:298-306.

Parra M, Gascard P, Walensky LD, Gimm JA, Blackshaw S, Chan N, Takakuwa Y, Berger T, Lee G, Chasis JA, Snyder SH, Mohandas N, Conboy JG (2000) Molecular and functional characterization of protein 4.1B, a novel member of the protein 4.1 family with high level, focal expression in brain. J Biol Chem 275:3247-3255.

Rogers CA, Maron C, Schulteis C, Allen WR, Heinemann SF (2001) Afadin, a link between AMPA receptors and the actin cytoskeleton. Soc Neurosci Abstr 27:32.16.

Rubio ME, Wenthold RJ (1997) Glutamate receptors are selectively targeted to postsynaptic sites in neurons. Neuron 18:939-950.

Scott C, Keating L, Bellamy M, Baines AJ (2001) Protein 4.1 in forebrain postsynaptic density preparations: enrichment of 4.1 gene products and detection of 4.1R binding proteins. Eur J Biochem 268:1084-1094.

Shen L, Liang F, Walensky LD, Huganir RL (2000) Regulation of AMPA receptor GluR1 subunit surface expression by a $4.1 \mathrm{~N}$-linked actin cytoskeletal association. J Neurosci 20:7932-7940.

Sheng M, Sala C (2001) PDZ domains and the organization of supramolecular complexes. Annu Rev Neurosci 24:1-29.

Sommer B, Keinänen K, Verdoorn TA, Wisden W, Burnashev N, Herb A, Kohler M, Takagi T, Sakmann B, Seeburg PH (1990) Flip and flop: a cell-specific functional switch in glutamate-operated channels of the CNS. Science 249:1580-1585.

Song I, Kamboj S, Xia J, Dong H, Liao D, Huganir RL (1998) Interaction of the $N$-ethylmaleimide-sensitive factor with AMPA receptors. Neuron 21:393-400.

Srivastava S, Osten P, Vilim FS, Khatri L, Inman G, States B, Daly C, DeSouza S, Abagyan R, Valtschanoff JG, Weinberg RJ, Ziff EB (1998) Novel anchorage of GluR2/3 to the postsynaptic density by the AMPA receptorbinding protein ABP. Neuron 21:581-591.

Walensky LD, Gascard P, Fields ME, Blackshaw S, Conboy JG, Mohandas N, Snyder SH (1998) The 13-kD FK506 binding protein, FKBP13, interacts with a novel homologue of the erythrocyte membrane cytoskeletal protein 4.1. J Cell Biol 141:143-153.

Walensky LD, Blackshaw S, Liao D, Watkins CC, Weier HU, Parra M, Huganir RL, Conboy JG, Mohandas N, Snyder SH (1999) A novel neuronenriched homolog of the erythrocyte membrane cytoskeletal protein 4.1 J Neurosci 19:6457-6467.

Xia J, Zhang X, Staudinger J, Huganir RL (1999) Clustering of AMPA receptors by the synaptic PDZ domain-containing protein PICK1. Neuron 22:179-187.

Yamakawa H, Ohara O (2000) Comparison of mRNA and protein levels of four members of the protein 4.1 family: the type II brain $4.1 / 4.1 \mathrm{~B} /$ KIAA0987 is the most predominant member of the protein 4.1 family in rat brain. Gene 248:137-145.

Yamakawa H, Ohara R, Nakajima D, Nakayama M, Ohara O (1999) Molecular characterization of a new member of the protein 4.1 family (brain 4.1) in rat brain. Brain Res Mol Brain Res 70:197-209.

Zhu JJ, Esteban JA, Hayashi Y, Malinow R (2000) Postnatal synaptic potentiation: delivery of GluR4-containing AMPA receptors by spontaneous activity. Nat Neurosci 3:1098-1106. 